\title{
Understanding the Impact of Empowerment on Employees Innovation Performance: Evidence from the Jordanian Hotel Industry
}

\author{
Mousa Masadeh Samer M. Al-Sabi* Mukhles M. Al-Ababneh \\ Associate Professor, Department of Hotel and Tourism Management, Petra College for \\ Tourism and Archaeology, Al-Hussein Bin Talal University, P. O. Box 20, Ma'an 71111, Jordan
}

\begin{abstract}
This research aimed to measure the impact of empowerment on employees' innovation performance at five-star hotels in Jordan. The research applied the two main perspectives of empowerment (i.e., structural empowerment and psychological empowerment). A 35-item questionnaire, measuring empowerment and innovation performance, was distributed to 400 employees working in 12 five-star hotels in Jordan with a 63.5 response rate. Principle component analysis was utilized to determine the factor structure for both empowerment and innovation performance and regression analysis to determine the impact of empowerment on innovation performance. The results reveal that both forms of empowerment have a positive and significant impact on innovation performance. However, structural empowerment has a stronger impact on innovation performance than psychological empowerment. The results also show that integrating the two perspectives of empowerment together has clearly a higher level of impact on innovation performance than structural and psychological empowerment does when both taken separately. This research provides new insights into the existing literature, implications and directions for future research.
\end{abstract}

Keywords: employee empowerment, structural / psychological empowerment, innovation performance, hotels, and Jordan

DOI: $10.7176 / \mathrm{JTHS} / 44-02$

Publication date:October $31^{\text {st }} 2019$

\section{Introduction}

Empowerment and innovation are both commonly considered as a strategic tool for improving the performance of the hotel industry, a key driver of economic development, and a vital role in competition between hotels in the hotel industry. The existence of globalization, the rapid change of technology and customer demands has created a challenging and intense competition environment. Thus, the service organisations in general and hotels in particular must reserve a sustainable competitive advantage distinguished from others in terms of their products and services. Therefore, it has become necessary as a suggestion for the hotels in Jordan to improve their ability to innovate in order to sustain its existence and improve their services (Rodriguez, Hechanova and Regina. 2014). Furthermore, it has been seen that the focus of hotel organisations in Jordan has been limited to innovation performance. However, the management literature has approved that both empowerment and innovation have become two main constituents of organisation effectiveness and its offered services (Black and Porter, 2000).

Responding to rapid changes in the business environment, competitive strategies and customer demands (Cho et al., 2006), hotels need critical human resource in terms of creativity, skills, knowledge, ideas and synergy (Sreenivas, 2014). In this regard, empowerment emerged as an important and most preferred management practice for handling these rapidly changing and complex situations, with the purpose of establishing a satisfactory environment that can respond to customer demands, improve the quality of service (Ginnodo, 1997), and enhance operation performance, increase profitability, creativity and innovation (Lashley, 1995, 1999; Meihem, 2004; Çuhadar, 2005; Ueno, 2008; and Biron and Bamberger, 2010).

Empowering employees is an approach to better overall organisational strategy harmonizing performance of employees. Employees feel that they can add valuable contributions to their organisations (i.e. participate in decision-making, provide new ideas, and present better ways of doing work), and those employees are more motivated and more productive in the work (Kemp and Dwyer, 2001). Research suggests that empowerment can enhance employees' innovation performance (Sreeniva, 2014 and Uzunbacak, 2015), particularly in the hospitality industry (Nadeem et al., 2018; and Ergun, 2018) and thus a way to improve workplace environments and help organisations function effectively (Erstad, 1997).

Empowerment has been studied very well in the previous researches, but the role that empowerment plays in employees' innovation performance is still under-researched. How empowerment influences innovation performance remains a relatively unexplored research area. There is therefore a need to examine, from the employees' perspective, the levels of empowerment that are evident in the hotel industry and the influence of empowerment on innovation performance. This study was conducted in five-star hotels in Jordan. Many previous researches on empowerment and innovation performance have been conducted in the context of western economies 
and very little research has been done in the Middle East in general and Jordan in particular. However, there is evidence to suggest that different geographic or industrial contexts, cultural values, as well as demographic factors can change the nature of relationship between empowerment and innovation performance (e.g. Sreeniva, 2014; Nadeem et al., 2018; Ergun, 2018).

\section{Literature Review}

\subsection{Empowerment}

The concept of empowerment has been previously studied, defined and measured differently. Each author has seen it from different angle and consequently "meaning different things to different people" (Quinn and Spreitzer, 1997, P. 37). Some of this literature, (i.e. Kanter, 1983; Ginnodo, 1997; Eylon and Bamberger, 2000 and Mills and Ungson, 2003), refers to empowerment as a structural/rational perspective. This perspective presents empowerment as a management technique which entails sharing and delegating the power and control between managers and their employees (Kanter, 1983). Others defined empowerment as organisational policies, practices and structures that grant employees greater latitude to make decisions and exert influence regarding their work (Eylon and Bamberger, 2000 and Mills and Ungson, 2003). On the whole, the definitions of structural empowerment are centred on the idea of sharing power between employers and employees (Al-Sabi, 2011). In this sense, empowerment is seen where "employees and managers solve problems and take decisions that were traditionally reserved to higher levels of the organisation" (Ginnodo, 1997, p3). The focus here then is on the actions and behaviours managers and supervisors use to empower their employees.

Empowerment from a structural/relational perspective has been difficult to conceptualise and this due to the multiple dimensions of empowerment that have emerged in the literature. Despite this, some researchers continue to maintain their conceptualisations as one dimensional construct. For example, Savery and Luks (2001) measured empowerment as the influence of sharing power with employees to improve organisational performance. Further, Hartline and Ferrell (1996) and Chebat and Kollias (2000) measured empowerment as the degree to which employees use their own initiative and judgement whilst performing their jobs. However, many researchers agree that empowerment consists of several dimensions. Where much consensus exists that that the core element of empowerment involves giving employees discretion (Bowen and Lawler, 1992; and Rafiq and Ahmed, 1998), other dimensions often added to this to form the construct include information sharing, responsibility, rewards, accountability, trust, autonomy, knowledge and resources (Bowen and Lawler, 1992; Rafiq and Ahmed, 1998; Randolph and Sashkin, 2002; and Siebert et al, 2004).

The difference between these authors in conceptualisations structural/rational empowerment is dependent on what are they looking to investigate in their studies. For example, in 2004 Siebert and others, report information sharing is a dimension of empowerment, while Melhem (2004) reports it as an antecedent to empowerment. Melhem (2004) demonstrates that sharing information with employees should increase their knowledge and consequently they become better at exercising the empowerment they have been given, thus information sharing becomes a precursor of empowerment rather than a constituent of it. To define structural/rational empowerment in the context of this research, this research assumes that that training, rewards systems, and management style are the important factors of structural empowerment and that management should focus on the importance of these factors while implementing structural empowerment (Al-Sabi, 2011). Thus, this research defines structural empowerment as "the extent to which front line employees believe that they have been given the autonomy and authority to act independently which may derive from aspects such as training, reward systems and management style" (Al-Sabi, 2011, p.98).

The other parts of the literature refer to empowerment as a psychological perspective. Such a perspective can be viewed as an individual's feeling toward their jobs as well as individual's assessment of their own ability to perform their jobs. More specifically, the psychological perspective focuses on the employees' intrinsic motivation rather than on the managerial practices used to increase the individuals' levels of power. Power here means energy, thus to empower can also mean to energize (Thomas and Velthouse, 1990). That is, empowerment is conceptualized here as a state of mind, rather than something management does to employees. Consistent with that, Spreitzer's $(1995,1996)$ research has provided empirical support for the notion that psychological empowerment can be seen as a single construct composed in four dimensions: Meaning, competence, self-efficacy, and impact. Together, these four dimensions reflect an individual's active orientation to his or her work role (Thomas and Velthouse, 1990).

Lee and Koh (2001) argued that the term empowerment is still ambiguous conceptually, and is often used interchangeably with similar words, such as authority delegation, motivation, self-efficacy, job enrichment, employee ownership, self-determination, self-control, self-influence, self-leadership, high-involvement, and participative management. They therefore suggested that empowerment should really be seen as a new concept defining it as: "The psychological state of a subordinate perceiving four dimensions of meaningfulness, competence, self-determination and impact, which is affected by the empowering behaviours of the supervisor" (Lee and Koh, 2001, p.686). 
The underlying logic here is that employees will have their own individual perceptions or feelings of (psychological) empowerment which will in some ways influence their behaviour and performance at work (Odeh, 2008). These feelings of empowerment will in part be formed by the actions and behaviours of their managers and supervisors who are attempting to develop an employment environment (structural empowerment) that supports employees in taking control of their own work (Amenumey and Lockwood, 2008). As such, both structural empowerment and psychological empowerment, which will form full employees' empowerment, should serve as a key drive to enable employees take ownership of tasks should they arise, as well as take the necessary and immediate action toward them.

However, Johnson and Redmond (1998) confirmed that adopting employee empowerment is not an easy task. Management in general and senior managers in particular who accept to adopt empowerment agree so because they know there are specific organizational goals cannot be achieved without involving the whole workforce in the service organization. In such cases, the service organization is then required to acquired the knowledge, experience and skills from employees and be assured about their commitment to the service organization. Thus, empowerment is about achieving organizational goals and preparing the entire workforce from structural and psychological side in making the service organization successful.Therefore, Empowerment has become a strategic approach for the success of different service organizations and seen as a part of an integrated plan to achieve organizational improvements in areas such as operational effectiveness, quality management, customer care and continuous improvement (Johnson and Redmond, 1998). In addition, it provides employees with freedom to do their work effectively and to make decisions (Lashley, 2001).

The literature of empowerment in the service sector is also revealed that employee empowerment can provide different experiences and benefits to employees (Lashley, 2001), and therefore empowerment cab be seen as a way to improve operations (i.e. creativity and innovation), and increase profit (Lashley, 1995). For example, empowered employees in the hospitality industry are more committed to improving service quality due to empowerment provides employees with the necessary autonomy and authority that achieve successful organisational outcomes (Lashley, 1995). Thus, employee empowerment has developed increasing influence in the hospitality industry (Kruja, Ha, Drishti, \& Oelfke, 2016) and focused on the exercise of the full range of decision making authority and power that is transferred to employees (Robbins et al., 2002). Consequently, empowerment can enhance employees to be able in creating and implementing anything with job-related issues without referring to senior level management (Klidas, 2001).

\subsection{Innovation Performance}

Although the management literature of innovation shows clearly the main differences between creativity and innovation, some researchers still provide definitions of these two terms differently which lead us to be confused. For example, innovation is defined as "any idea or practice perceived to be new by the adopting organization" (Ergun, 2018, p.61). Consistent with that, innovation is also defined as any internally generated or purchased device, system, policy, program, process, product, or service that is new to the adopting organization (Daft, 1982; Damanpour and Evan, 1984).

To the best of our knowledge, these two definitions of innovation in the preceding paragraph are to some extent not the definitions of innovation but instead they are for creativity. Precisely, creativity means 'the development of potential new and useful ideas' (Al Ababneh, 2014), the production of new and useful ideas in any domain (Oldham and Cummings, 1996), and producing many exciting ideas and new concepts (Ergun, 2018). While, innovation is defined as 'the successful implementation of new and useful ideas at organisational level' (Amabile, 1996, 1997), 'the successful implementing of the generated ideas or products at the organisational level' (Oldham and Cummings, 1996), and 'the sustainability of these ideas by finding applications that result in new products, processes and services that enable creative ideas to reach the company with higher sales figures, market share and profitability (Rodriguez, Hechanova and Regina, 2014).

Creativity and innovation are two separate and different terms, however, some parts of innovation literature present them interchangeably (Scott and Bruce, 1994; Awamleh, 1994; Martins and Terblanche, 2003; Mostafa, 2005), consequently both terms are very much linked in individuals' minds as one term and they still use these terms interchangeably. For example, creativity or innovation in one definition presented as a "systematic development and practical application of a new idea" (Mustafa, 2005, p.8). It can be noted from Mustafa's definition for both terms that they are two faces for one coin named innovation performance. More precisely, innovation performance is composed of two stages: the development of new idea (creativity) and practical application of new idea (innovation), this was supported by Ford (1996) who stated that creativity and innovation are fundamentally the same phenomenon, but they take place at various levels of analysis. Therefore, innovation performance cannot be achieved without the existence of creativity and innovation together.

On the whole, creativity focuses on creating, producing, generating and development of something new (i.e. ideas, products, services, policies, procedures), and accordingly it was considered to be the first step of the innovation performance, while, innovation focuses on implementing, doing and conducting something new (i.e. 
ideas, products, services, policies and procedures) and consequently it was considered the second step of the innovation performance. Therefore, it becomes very much necessary in this research to further define innovation performance. This research defines innovation performance as the process of creating and implementing new and useful ideas, products, services, policies and procedures at all levels in the service organisation

Innovation performance is considered as the backbone for organisational effectiveness (Basadur et al., 2002), and for finding new solutions to business and customer problems (Herbig and Jacobs, 1996; Mostafa, 2005). Successful organisations are more dependent on creativity and innovation than ever (Wong and Pang, 2003). This is due to the fact that innovation performance provides service organisations the competitive advantage that enables them to achieve superior performance, and to response to changing customer requirements and competitive threats.

In the hospitality industry, innovation performance has become a strategic approach for successful hospitality organisations. Innovations in hospitality are mostly important assets and have different forms starting from create and implement new service to new market, to a slight modification on the present services, or to provide an added value to the present services (Ottenbacher and Gnoth, 2005). In such industry that is characterised with a turbulent and unstable environment has forced hospitality organisations to modify and update their services to meet the change in their customers ${ }^{\text {ee }}$ needs and wants, and survive in the market. As a result, the implementation of innovation performance has becomes an important technique for successful hospitality organisations.

Innovation performance provides several benefits to service organisations, but the major benefit is the competitive advantage that has been achieved by organisations (Ottenbacher and Gnoth, 2005). Innovation performance in the hospitality industry can be rapidly overcome therefore continuous innovation performance becomes an important to face barriers in the competitive market (Harrington, 2004). Successful innovation performance is not always clear for managers in the hospitality industry. However, creating an organisational culture that encourages creativity and innovation are vital features of organisations and these simply refere back to the role of innovation management (Ottenbacher and Harrington, 2007).

\subsection{Empowerment and Innovation Performance}

Competitive environment, the changes in customers' demands and globalization are the key factors that have led the service organisations to empower their employees, attempting to increase their profitability, creativity and innovation (Çuhadar, 2005). Both empowerment and innovation are of great importance for organizations to be successful in the long term, to enlarge, and to survive (Sreeniva, 2014 and Uzunbacak, 2015). For these reasons, empowerment, which gives employees the autonomy and authority to act independently, make decisions, and helps to create new research fields, new ideas, products and markets and thus contributes to the service organisation growth (Al- Sabi, 2011 and Al Zahrani, 2012).

As mentioned earlier, two main perspectives of empowerment have presented namely; structural empowerment and psychological empowerment. Integrating these two main perspectives together, the supervisor's behaviour and employee's perceptions as cause and effect of empowerment are suggested to be important in implementing employee empowerment and achieving the desired outcomes (Lee and Koh, 2001). In other words, the ability that the employer has to empower his/her employees would affect the employees' assessment of the four dimensions of empowerment. Thus, the ability the employer has to empower employees would affect the extent to which an employee would find his/her job meaningful, feel confident of having the skills required to perform their job successfully (competence), feel he/she has authority to determine how to do the job and make a difference to the organisation outcomes by achieving the job purpose (Al-Sabi, 2011). This was supported by Uzunbacak (2015) who indicated that the employees are appreciated the efforts of empowerment, participate in management, have the authority to make decisions and to produce new ideas and that managers attempt to create an environment which will facilitate employees' creativity and innovativeness as well as encourages employees to behave innovatively. In this created environment, the employees will feel empowered and be able to produce and implement new ideas (Köksal, 2011).

Empowered employees believe they are autonomous and have an impact, thus they are likely to be creative and feel less constrained than others by technical or rule-bound aspects of work (Amabile, 1988). Spreitzer (1995) tested the relationship between psychological empowerment and innovation performance. She found that psychological empowerment was positively related to innovation performance. In another study, the relationships between psychological empowerment and innovation were examined. The findings of the study, showed that empowerment causes higher level of innovation performance (Bhatnagar, 2012).

Bolat (2008) demonstrates that employee empowerment not only has a significant impact on employees' efficiency, work satisfaction, quality, and customer satisfaction, but also has an increase to the demand and efforts to create innovation. Allocating enough time, education and resource for the employees makes a positive impact on employees' self-sufficiency, work satisfaction, confidence and the meaningfulness of work. The employees with these specifications feel themselves more empowered, increase their efficiency and productivity within the organization, and become the source of new ideas and innovation (Kahreh et al, 2011).

In the light of the preceding discussions and findings, this research has identifies a number of gaps that 
previous researches did not investigate. First, previous researches have measured empowerment and innovation performance from the management perspective and very few from the employees perspective. Second, most of the previous researches that investigate the relationship between empowerment and innovation performance were conducted in a western countries and few conducted in developing countries such as Jordan. Third, most of the previous researches have not yet been examined structural empowerment and psychological empowerment as a whole on innovation performance in the hospitality industry and most of these researches tend to adopt either structural empowerment or psychological empowerment separately. Therefore, this research is considered as one of the first researches that measures the potential impact of both structural empowerment and psychological empowerment as a whole on innovation performance from the employees' perspective in five star hotels in Jordan.

\section{Theoretical Framework}

Figure 1 illustrates the research's theoretical framework. The independent variables were structural empowerment, psychological empowerment and employee empowerment, while the dependent variable was innovation performance.

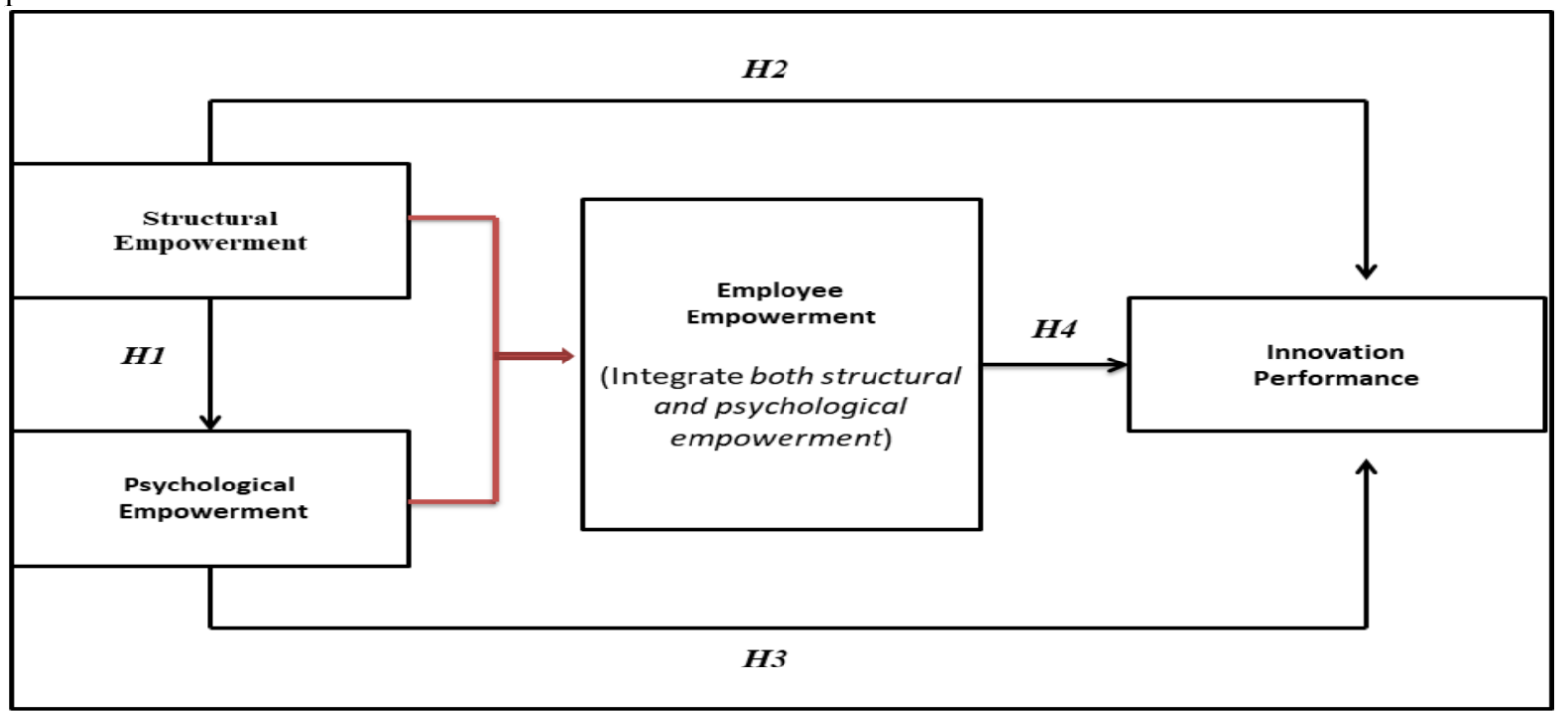

Figure1. Research's Theoretical Framework

In figure 1, the proposed research's theoretical framework suggests that structural empowerment will have a direct influence on psychological empowerment and this in turn would create for the employees a state of full empowerment (employee empowerment). This means that implementing structural empowerment effectively will create for employees an environment that enables them to feel empowered. Accordingly, employee empowerment would potentially have a significant influence on innovation performance more than the influence of structural empowerment and psychological empowerment taken individually. It suggests also that structural empowerment from side and psychological empowerment from the other side would have a direct influence on innovation performance. This possibly implies that employees will have their own individual perceptions or feelings of (psychological) empowerment which will in some ways influence their behaviour and action (structural empowerment) and performance at work (innovation performance).

\subsection{Research Hypotheses}

Based on the literature review highlighted above, the following hypotheses were developed:

Hypothesis1: Structural empowerment will have a positive and significant impact on psychological empowerment Hypothesis 2: Structural empowerment will have a positive and significant impact on innovation performance. Hypothesis 3: Psychological empowerment will have a positive and significant impact on innovation performance. Hypothesis 4: Integrate both forms of empowerment; structural and psychological empowerment (employee empowerment) will have a higher level of positivity on innovation performance than structural and psychological empowerment that were both taken separately

\section{Research Methodology}

\subsection{Research Design and Implementation}

In order to figure out the potential role of empowerment that plays on innovation performance at five star hotels in Jordan, a quantitative approach based on a self-administered questionnaire was used to be the best approach with separate sections of the instrument measuring the two variables; empowerment and innovation performance from the employees' perspective and collecting demographic data. Many of the international hotel companies in 
Jordan, interested in employee empowerment and innovation performance, agreed to participate in the research and facilitate access for the researchers to distribute the questionnaire among the employees.

The data then were collected from a sample of all employees working in five-star hotels in Jordan. The sample size amounted to a total of 400 employees. The questionnaire was distributed and collected by the researchers, using a face-face approach. Of 400 distributed questionnaires, 254 usable questionnaires were gathered and finally coded. This represents 63.5 percent of the total questionnaires distributed earlier. Data analysis included descriptive analysis, exploratory factor analysis, and multiple regression analysis. All tests performed using SPSS version 21.

Two adopted scales were used to measure the relationship between empowerment and innovation performance. The questionnaire of this research consisted of three sections. The first section measured employees' perceptions of empowerment that including both structural empowerment and psychological empowerment. Structural empowerment includes 14 items, selected from Haye's (1994) scale and psychological empowerment includes 12 items, selected from Spreitzer's (1995) scale. The second section measured employees' perceptions of innovation performance that includes 11 items, selected from Prajogo and Sohal (2003) scale. Both empowerment and innovation performance were measured on a five-point likert scale where $1=$ strongly disagree and $5=$ strongly agree. Demographic questions on gender, age, education, working department and work experience were also included in the last section of the questionnaire. The questionnaire was translated from English to Arabic using a back translation procedure.

\subsection{Research Results}

\subsubsection{Demographic Characteristics}

A descriptive analysis was used to describe the research's sample. Table 1 presents the demographic profile of the respondents.

Table 1: The Demographic Characteristics

\begin{tabular}{|l|l|l|}
\hline Characteristics & $\begin{array}{l}\text { Sample } \\
(N=254)\end{array}$ & Percentage \\
\hline Gender & 200 & $79 \%$ \\
\hline Male & 54 & $21 \%$ \\
\hline Female & 68 & $27 \%$ \\
\hline Age & 86 & $34 \%$ \\
\hline 25 or under & 84 & $33 \%$ \\
\hline $26-35$ & 13 & $5 \%$ \\
\hline $36-45$ & 3 & $1 \%$ \\
\hline $46-55$ & \multicolumn{2}{|l|}{} \\
\hline 56 and more & 160 & $63 \%$ \\
\hline Education & 89 & $35 \%$ \\
\hline Secondary school or less & 5 & $2 \%$ \\
\hline Undergraduate & \multicolumn{2}{|l|}{} \\
\hline Postgraduate & 147 & $58 \%$ \\
\hline Working Department & 107 & $42 \%$ \\
\hline Front of the house & \multicolumn{2}{|l|}{} \\
\hline Back of the house & 18 & $7 \%$ \\
\hline Experience & 79 & $31 \%$ \\
\hline Less than one year & 76 & $32 \%$ \\
\hline 2-4 years & 81 & \\
\hline $5-7$ years & & \\
\hline 8 year and more & & \\
\hline
\end{tabular}

Table 1 illustrates that $79 \%$ of respondents were male and only $21 \%$ were female. These numbers close to the hotels workforce statistics in Jordan, for instance, males consist of $92 \%$ and $8 \%$ is females (Jordanian Ministry of Tourism and Antiquities, 2019). A $27 \%$ of respondents were 25 years of age and under, $34 \%$ were between 26 and $35,33 \%$ were between 36 and 45 , and only $6 \%$ were 46 or over. The education reported by respondents showed that $63 \%$ had secondary school or less, $35 \%$ had undergraduate degree and only $2 \%$ had a postgraduate degree. For working department, the majority of employees $58 \%$ were working in the front of the house and the other $42 \%$ were working in the back of the house. Finally, $7 \%$ percent of the respondents reported working in five-star hotels in Jordan for less than 1 year, 31\% between 2 and 4 years, $30 \%$ between 5 and 7 years, and finally $32 \%$ reported working longer than 8 years. All aspects of this demographic profile reflect the known composition of the workforce in the Jordanian hospitality industry. 


\subsubsection{Validity and Reliability of the Scales}

The scales utilised in this research were originally developed in a western culture and successfully showed good validity and reliability results through different working contexts. Though, it is important to purify these scales in a non-western culture as this research conducted in Jordan, and examine their validity and reliability. Therefore, an exploratory factor analysis was conducted to establish the construct validity and cornbach's alpha was used to assess the construct reliability. A principal component analysis with Varimax rotation was used to show the significant factor loadings for this study. The following tables present the final outcomes of the factor analysis after rotation.

Table2: Output of Factor Analysis for Structural Empowerment

\begin{tabular}{|l|l|l|}
\hline Items & \multicolumn{2}{l|}{ Factor loadings } \\
\hline Structural Empowerment & $\begin{array}{l}\text { Item loading } \\
\alpha=860\end{array}$ & Communality \\
\hline SE01, I am allowed to do almost anything to do a high quality job & .755 & .570 \\
\hline SE03, I have authority to correct problems when they occur & .790 & .624 \\
\hline SE11, I am able to make changes in my job when I deem them appropriate & .699 & .488 \\
\hline SE15, I have a lot of responsibility in my job & .753 & .567 \\
\hline SE16, I am encouraged to use initiative when dealing with job-related problems & .757 & .574 \\
\hline SE17, I have a lot of control over how I do my job & .717 & .514 \\
\hline SE19, I am encouraged to handle job-related problems & .714 & .509 \\
\hline & & \\
\hline Eigen-value & 3.8 & \\
\hline Percentage of variance explained & $54.9 \%$ & \\
\hline Cumulative (Total explained) & $54.9 \%$ & \\
\hline
\end{tabular}

As presented above in table 2, the result of the factor analysis reveals a single factor with an Eigenvalue exceeding 1 . The one component solution explained a total of $55 \%$ of variance. These results provide evidence for the construct validity of the scale. Item loadings on this construct ranged from 0.69 to 0.79 and all the items loadings were above 0.65 . The obtained Cronbach alpha shows that structural empowerment as one factor construct has clearly exceeded the minimum recommended value $(\alpha=0.70)$, which acceptable for exploratory research (Hair et al., 2010).

Table3: Output of Factor Analysis for Psychological Empowerment

\begin{tabular}{|c|c|c|c|}
\hline Items & Factor loadings & & \\
\hline Psychological Empowerment & $\begin{array}{l}\text { Item Loading } \\
\text { (Attitude ) } \\
\alpha=.902\end{array}$ & $\begin{array}{l}\text { Item Loading } \\
\text { (Influence) } \\
\alpha=.870\end{array}$ & Communality \\
\hline MPE02, The work I do is very important to me & .843 & & .765 \\
\hline $\begin{array}{l}\text { CPE04, I am self-assured about my capability to perform } \\
\text { my work activities }\end{array}$ & .844 & & .799 \\
\hline CPE05, I have mastered the skills necessary for my job & .826 & & .768 \\
\hline MPE07, The work I do is meaningful to me & .883 & & .791 \\
\hline $\begin{array}{l}\text { SPE22, I can decide on my own how to go about doing my } \\
\text { work }\end{array}$ & & .887 & .815 \\
\hline $\begin{array}{l}\text { SPE23, I have considerable opportunity for independence } \\
\text { in how I do my job }\end{array}$ & & .880 & .820 \\
\hline $\begin{array}{l}\text { IPE24, My impact on what happens in my department is } \\
\text { large }\end{array}$ & & .812 & .750 \\
\hline Eigen-value & 4.1 & 1.3 & \\
\hline Percentage of variance explained & 59.19 & 19.48 & \\
\hline Cumulative (Total explained) & & & 78.67 \\
\hline
\end{tabular}

In table 3 , the result of the factor analysis reveals a dual-dimensional structure for psychological empowerment with an Eigenvalue exceeding 1 . The two factor solution explained a total of $79 \%$ of variance. These results provide evidence for the construct validity of the scale. The first factor is named in the previous researches 'attitude' which reflects two factors of the original scale (meaning and competence). This factor is made up of two items from 'meaning factor' and two from 'competence factor'. Item loadings on this factor ranged from 0.82 to 0.88. The second factor is also named in the previous studies 'influence', reflects the last two factors of the original scale (impact and self-determination). This factor is formed from two items of 'self-determination' factor and one item of 'impact' factor. Item loadings on this factor were above 0.80 . The obtained Cronbach alpha shows that the two factors of psychological empowerment attitude and influence have clearly exceeded the minimum 
recommended value $(\alpha=0.7)$. Therefore, these two factors appear to be valid and reliable. Table4: Output of Factor Analysis for Innovation Performance

\begin{tabular}{|l|l|l|}
\hline Items & Factor loadings \\
\hline Innovation Performance & $\begin{array}{l}\text { Item loading } \\
\alpha=.968\end{array}$ & Communality \\
\hline INN1, The level of newness of our new products/services. & .874 & .765 \\
\hline INN2, The competitiveness of our technology. & .914 & .835 \\
\hline INN3, The innovation of our technology in new product/service development. & .915 & .837 \\
\hline INN4, The updated-ness of our technology in hotel's processes. & .871 & .759 \\
\hline INN5, The speed of our new product/service development. & .899 & .808 \\
\hline $\begin{array}{l}\text { INN6, The speed of our adoption of the latest technological innovations in } \\
\text { hotel's processes. }\end{array}$ & .909 & .826 \\
\hline INN7, The number of our new products/services introduced to the market. & .893 & .797 \\
\hline INN8, The rate of our change in processes, techniques and technology. & .904 & .817 \\
\hline INN9, The number of our new products/services that is first-to-market. & .865 & .748 \\
\hline & & \\
\hline Eigen-value & 7.19 & \\
\hline Percentage of variance explained & 79.90 & \\
\hline Cumulative (Total explained) & 79.90 & \\
\hline
\end{tabular}

As shown above in table 4, the factor analysis reveals unexpected and different results from the initial two factors (product innovation and process innovation). The results also show a single factor with an Eigenvalue exceeding 1 . The one factor solution explained a total of $80 \%$ of variance and this provides an evidence for the construct validity of the innovation performance scale. Item loadings on this construct ranged from 0.86 to 0.91 and all the items loadings were above 0.85 . The obtained Cronbach alpha shows that innovation performance as one factor construct has clearly exceeded the minimum recommended value $(\alpha=0.70)$, which is 0.96 . Therefore, innovation performance scale with only one factor and 9 items appears to be valid and reliable.

Finally, it is very important to notice that the number of the items that are used for measuring the constructs of this research were below 10 items. In such cases, Pallant (2010) suggests that two measures of internal consistency should be used: the item total correlation and the inter item correlation as shown in table 5. Hair et al., (2006, p. 137) indicated that the inter-item correlation should be more 0.30 and the correlation of the items to the summated scale should be more than 0.50 to be meaningful, while, Briggs and Cheek (1986) recommended an optimal range for the inter-item correlation of 0.20 to 0.40 . Table 5 shows the results inter-item correlation for the constructs of this research. 
Table5: Inter-Item Correlation for the Variables Study

\begin{tabular}{|c|c|c|c|c|c|c|c|c|c|c|}
\hline & SE01 & SE03 & SE11 & SE15 & SE16 & SE17 & SE19 & SE & & \\
\hline $\begin{array}{l}\text { SE01 } \\
\end{array}$ & 1 & & & & & & & & & \\
\hline SE03 & $.635 * *$ & 1 & & & & & & & & \\
\hline SE11 & $.403 * *$ & $.445 * *$ & 1 & & & & & & & \\
\hline SE15 & $.554 * *$ & $.508 * *$ & $.385^{* *}$ & 1 & & & & & & \\
\hline SE16 & $.537 * *$ & $.514 * *$ & $.439 * *$ & $.512 * *$ & 1 & & & & & \\
\hline SE17 & $.407 * *$ & $464 * *$ & $.538 * *$ & $.460 * *$ & .417 & 1 & & & & \\
\hline SE19 & $.352 * *$ & $.495 * *$ & $.454 * *$ & $.471 * *$ & $493 * *$ & $.458 * *$ & 1 & & & \\
\hline$* \mathrm{SE}$ & $.774 * *$ & $.789 * *$ & $.696^{* *}$ & $.741 * *$ & $.761 * *$ & $.709 * *$ & $.710 * *$ & 1 & & \\
\hline \multicolumn{11}{|c|}{ Correlation is significant at the 0.01 level (2-tailed). } \\
\hline & PE02 & PE04 & PE05 & PE07 & PE22 & PE23 & PE24 & PE & & \\
\hline PE02 & 1 & & & & & & & & & \\
\hline PE04 & $.736^{* *}$ & 1 & & & & & & & & \\
\hline PE05 & $.636^{* *}$ & $.760 * *$ & 1 & & & & & & & \\
\hline $\begin{array}{l}\text { PE07 } \\
\end{array}$ & $.711 * *$ & $.665^{* *}$ & $.690 * *$ & 1 & & & & & & \\
\hline PE22 & $.429 * *$ & $.435 * *$ & $.344 * *$ & $.207 * *$ & 1 & & & & & \\
\hline PE23 & $.317 * *$ & $.430 * *$ & $.459 * *$ & $.333 * *$ & $.727 * *$ & 1 & & & & \\
\hline $\begin{array}{l}\text { PE24 } \\
\end{array}$ & $.427 * *$ & $.427 * *$ & $.488 * *$ & $.386^{* *}$ & $654 * *$ & .687 & 1 & & & \\
\hline **PE & $.792 * *$ & $.828 * *$ & $.806 * *$ & $.739 * *$ & $714 * *$ & $.737 * *$ & $.756 * *$ & 1 & & \\
\hline \multicolumn{11}{|c|}{ Correlation is significant at the 0.01 level (2-tailed). } \\
\hline & INN01 & INN02 & INN03 & INN04 & INN05 & INN06 & INN07 & INN08 & INN09 & INN \\
\hline INN01 & 1 & & & & & & & & & \\
\hline INN02 & $.865^{* *}$ & 1 & & & & & & & & \\
\hline $\begin{array}{l}\text { INN03 } \\
\end{array}$ & $.750 * *$ & $.843 * *$ & 1 & & & & & & & \\
\hline INN04 & $.828 * *$ & $.857 * *$ & $.757 * *$ & 1 & & & & & & \\
\hline INN05 & $.765 * *$ & $.793 * *$ & $.809 * *$ & $.777 * *$ & 1 & & & & & \\
\hline INN06 & $.690 * *$ & $.774 * *$ & $.846^{* *}$ & $.720 * *$ & $.807 * *$ & 1 & & & & \\
\hline INN07 & $.760 * *$ & $.776^{* *}$ & $.779 * *$ & $.726^{* *}$ & $.742 * *$ & $.783 * *$ & 1 & & & \\
\hline INN08 & $.709 * *$ & $.764 * *$ & $.797 * *$ & $.722 * *$ & $.776^{* *}$ & $.833^{* *}$ & $.840^{* *}$ & 1 & & \\
\hline INN09 & $.673 * *$ & $.674 * *$ & $.770 * *$ & $.627 * *$ & $.762 * *$ & $.851 * *$ & $.775^{* *}$ & $.829 * *$ & 1 & \\
\hline$* * *$ INN & $.876^{* *}$ & $.913 * *$ & $.914 * *$ & $.871 * *$ & $899 * *$ & $.908 * *$ & $.893 * *$ & $.903 * *$ & $.866 * *$ & 1 \\
\hline
\end{tabular}

$* \mathrm{SE}=$ Structural Empowerment $* * \mathrm{PE}=$ Psychological Empowerment $* * * \mathrm{INN}=$ Innovation Performance

Table 5 shows that most of the inter-item correlations are significant and exceed the accepted level of 0.30 and the correlations with the summated scales: structural empowerment, psychological empowerment and innovation performance are all significant and above 0.50 , which indicate acceptable levels of reliability. 4.2.3. Descriptive Statistics of the Research's Variables

Having tested the validity and the reliability of the scales, descriptive analysis is another statistical test that was performed for the extracted dimensions and overall scales

Table 6: Output of the Descriptive Analysis ( $\mathrm{N}=254)$

\begin{tabular}{|l|l|l|l|l|}
\hline Scales & Extracted Factors & Mid-scale & Mean & Std. Deviation \\
\hline $\begin{array}{l}\text { Employee } \\
\text { Empowerment }\end{array}$ & Overall & 3 & 3.66 & .828 \\
\hline Structural Empowerment & Overall & 3 & 3.74 & .786 \\
\hline Psychological Empowerment & Overall & 3 & 3.84 & .831 \\
\hline \multirow{2}{*}{ Psychological Empowerment } & Attitude (1) & 3 & 4.00 & .945 \\
\cline { 2 - 5 } & Influence (2) & 3 & .981 \\
\hline Innovation Performance & Overall & 3 & 3.48 & 1.096 \\
\hline
\end{tabular}

In table 6 , it is necessary to note that all the scales of this research were computed by the means' scores of its sub-scales. The mean score for all the scales has clearly exceeded the mid-point scale 3 and ranged from 3.48 to 3.84. For employee empowerment, the scale was formed by merging structural empowerment items and psychological empowerment items and thus was computed by summing up its 14 items. The mean score for an overall scale is 3.66 with a standard deviation (S.D) at .828 . This shows the ability that the employer's behaviour (structural empowerment) has to empower his/her employees would affect the employees' assessment of the four dimensions of empowerment (psychological empowerment) was performed effectively and consequently the employees in the Jordanian hotels were highly believed that they were empowered structurally and psychologically. 
More specifically, the structural empowerment scale as one-factor was computed by summing up its 7 items. The mean score for an overall scale is 3.74 with standard deviation (S.D) at 0.786 . This means, the employees believe that they were give the autonomy and the authority to act independently and illustrates also they were highly structurally empowered.

With regards to psychological empowerment, an overall score was computed by summing up the two supscales; attitude and influence. The mean score for an overall is 3.84 with a standard deviation (S.D) at 0.768. This means that the employees perceived all the cognition of psychological empowerment effectively. On one hand, meaning and competence (attitude) with a mean score is 4.00 and on the other hand, self-determination and impact (influence) with a mean score is 3.62. Inevitably, the employees were highly psychologically empowered.

Regarding innovation performance, the scale as one-factor was computed by summing up its 9 items. The mean score for an overall scale is 3.48 with standard deviation (S.D) at 0.1.096. This illustrates that the employees were able create new ideas, products, services, policies and procedures and implemented effectively at all levels in the service organisation.

4.2.4. Correlation Analysis

Correlation analysis at this stage of the research provides an initial indicator of the relationships among the variables. Therefore, all the variables without the sub-scales were subjected to this analysis and presented in table 7.

Table 7: Output of the Correlation between Variables

\begin{tabular}{|l|l|l|}
\hline \multicolumn{2}{|l|}{} & Innovation Performance \\
\hline Structural & Pearson Correlation & $.622^{* *}$ \\
Empowerment & Sig. (2-tailed) & .000 \\
\hline Psychological & Pearson Correlation & $.495^{* *}$ \\
Empowerment & Sig. (2-tailed) & .000 \\
\hline Employee & Pearson Correlation & $.688^{* *}$ \\
Empowerment & Sig. (2-tailed) & .000 \\
\hline Innovation & Pearson Correlation & 1 \\
Performance & Sig. (2-tailed) & .000 \\
\hline
\end{tabular}

As shown in table 7, a high correlation appears between 'structural empowerment' and 'innovation performance' $(\mathrm{r}=0.622)$. The 'psychological empowerment' variable shows a medium correlation with 'innovation performance'. Interestingly, 'employee empowerment' variable shows a higher level of correlation with innovation performance variable than structural and psychological empowerment does separately. These finding confirm that structural empowerment and psychological empowerment were implemented effectively in Jordanian hotels and lead the employees to perform the process of creating and implementing new ideas, products, services and policies and procedures effectively.

\subsubsection{Testing Hypotheses}

For testing the hypotheses of this research, a multiple regression technique is performed. Multiple regression analysis is a statistical technique that can be used to analyse and measure the relationship between a single dependent variable and several independent variables (Hair, et al., 2010). In other words, this measure provides an idea about how well the independent variable will contribute in the dependent variable and show the overall prediction. In this research, all the variables are metric and therefore divided into independent, and dependent. Structural empowerment, psychological empowerment and full empowerment worked as the independent variables, and innovation performance worked as the dependent variable. Testing hypotheses is presented as follows:

Table 8: Regression Model Statistics Dependent Variable: Psychological Empowerment

\begin{tabular}{|c|c|c|c|c|c|}
\hline \multirow{2}{*}{ Independent } & \multicolumn{5}{|c|}{ Dependent } \\
\hline & \multicolumn{5}{|c|}{ Psychological Empowerment } \\
\hline \multirow{2}{*}{$\begin{array}{l}\text { Structural } \\
\text { Empowerment }\end{array}$} & $\boldsymbol{\beta}$ & $\underline{\mathbf{t}}$ & $\stackrel{\mathbf{P}}{\text { Value }}$ & $\mathbf{R}^{2}$ & F Ratio \\
\hline & .742 & 17.563 & .000 & .550 & 308.448 \\
\hline
\end{tabular}

As shown in table 8 , the result of the regression analysis reveals that structural empowerment is a significant predictor of psychological empowerment. Statistically, it can be seen from the above table that the value between structural empowerment and psychological empowerment is $(\beta=0.742$ and $\mathrm{P}$ value $<0.01)$. Finally, the overall model statistic in Table $8,\left(\mathbf{R}^{2}=0.550, p=0.000\right)$, supported the view that structural empowerment has a positive influence on psychological empowerment, and therefore empowered the employees structurally through given the autonomy and the authority to act independently leads them to feel psychologically empowered. Hence, the hypothesis one (H1) is supported. 
Table 9: Regression Model Statistics Dependent Variable: Psychological Empowerment

\begin{tabular}{|l|l|l|l|l|l|}
\hline \multirow{2}{*}{ Independent } & \multicolumn{5}{l}{} \\
\cline { 2 - 6 } & \multicolumn{5}{|l|}{ Dependent } \\
\hline \multirow{2}{*}{$\begin{array}{l}\text { Structural } \\
\text { Empowerment }\end{array}$} & $\boldsymbol{\beta}$ & $\underline{\mathbf{t}}$ & $\begin{array}{c}\underline{\mathbf{P}} \\
\text { Value }\end{array}$ & $\mathbf{R}^{\mathbf{2}}$ & F Ratio \\
\cline { 2 - 6 } & .622 & 12.612 & .000 & .387 & 159.073 \\
\hline
\end{tabular}

As shown in table 9, the result of the regression analysis reveals that structural empowerment is a significant predictor of innovation performance. Statistically, it can be seen from the above table that the value between structural empowerment and innovation performance is $(\beta=0.622$ and $\mathrm{P}$ value $<0.01)$. Finally, the overall model statistic in Table 9, $\left(\mathbf{R}^{2}=0.387, p=0.000\right)$, supported the view that structural empowerment has a positive influence on innovation performance, and therefore empowered the employees structurally through given the autonomy and the authority to act independently leads to make them able effectively to create and implement new ideas, services, products, policies and procedures and so on so forth. Hence, the hypothesis two (H2) is supported.

Table 10: Regression Model Statistics Dependent Variable: Innovation Performance

\begin{tabular}{|l|c|c|c|c|c|}
\hline \multirow{2}{*}{ Independent } & \multicolumn{5}{l}{ Dependent } \\
\cline { 2 - 6 } & \multicolumn{5}{|l|}{ Innovation Performance } \\
\hline \multirow{2}{*}{$\begin{array}{l}\text { Psychological } \\
\text { Empowerment }\end{array}$} & $\boldsymbol{\beta}$ & $\underline{\mathbf{t}}$ & $\begin{array}{c}\mathbf{P} \\
\text { Value }\end{array}$ & $\mathbf{R}^{\mathbf{2}}$ & F Ratio \\
\cline { 2 - 6 } & .495 & 9.050 & .000 & .245 & 81.895 \\
\hline
\end{tabular}

As shown in table 10, the result of the regression analysis reveals that psychological empowerment is a significant predictor of innovation performance. Statistically, it can be seen from the above table that the value between psychological empowerment and innovation performance is $(\beta=0.495$ and $\mathrm{P}$ value $<0.01)$. Finally, the overall model statistic in table $10,\left(\mathbf{R}^{2}=0.245, p=0.000\right)$, supported the view that psychological empowerment has a positive influence on innovation performance, and therefore this explains that the employees at Jordanian hotels had also high level of trust in their abilities and choices in influencing, initiating and regulating their own work. Consequently, this leads the employees to be able to create and implement new ideas, services, products, policies and procedures effectively. Hence, the hypothesis three (H3) is supported.

Table 11: Regression Model Statistics Dependent Variable: Innovation Performance

\begin{tabular}{|l|l|l|l|l|l|}
\hline \multirow{2}{*}{ Independent } & \multicolumn{5}{|l|}{ Dependent } \\
\cline { 2 - 6 } $\begin{array}{l}\text { Employee } \\
\text { Empowerment }\end{array}$ & $\boldsymbol{\beta}$ & $\underline{\mathbf{t}}$ & $\begin{array}{c}\underline{\mathbf{P}} \\
\text { Value }\end{array}$ & $\mathbf{R}^{\mathbf{2}}$ & F Ratio \\
\cline { 2 - 6 } & .688 & 15.049 & .000 & .473 & 226.461 \\
\hline
\end{tabular}

As shown in table 11, the result of the regression analysis reveals that employee empowerment is a significant predictor of innovation performance. Statistically, it can be seen from the above table that the value between employee empowerment and innovation performance is $(\beta=0.688$ and $\mathrm{P}$ value $<0.01)$. Finally, the overall model statistic in table $11,\left(\mathbf{R}^{2}=0.473, p=0.000\right)$, supported the view that employee empowerment has a positive influence on innovation performance, and therefore when the employees feel that they are empowered psychologically, which is formed as a result of employer's behaviour (structural empowerment), this leads to make them able at higher level to create and implement new ideas, services, products, policies and procedures effectively than structural empowerment and psychological empowerment were taken individually . Hence, the hypothesis four (H4) is supported.

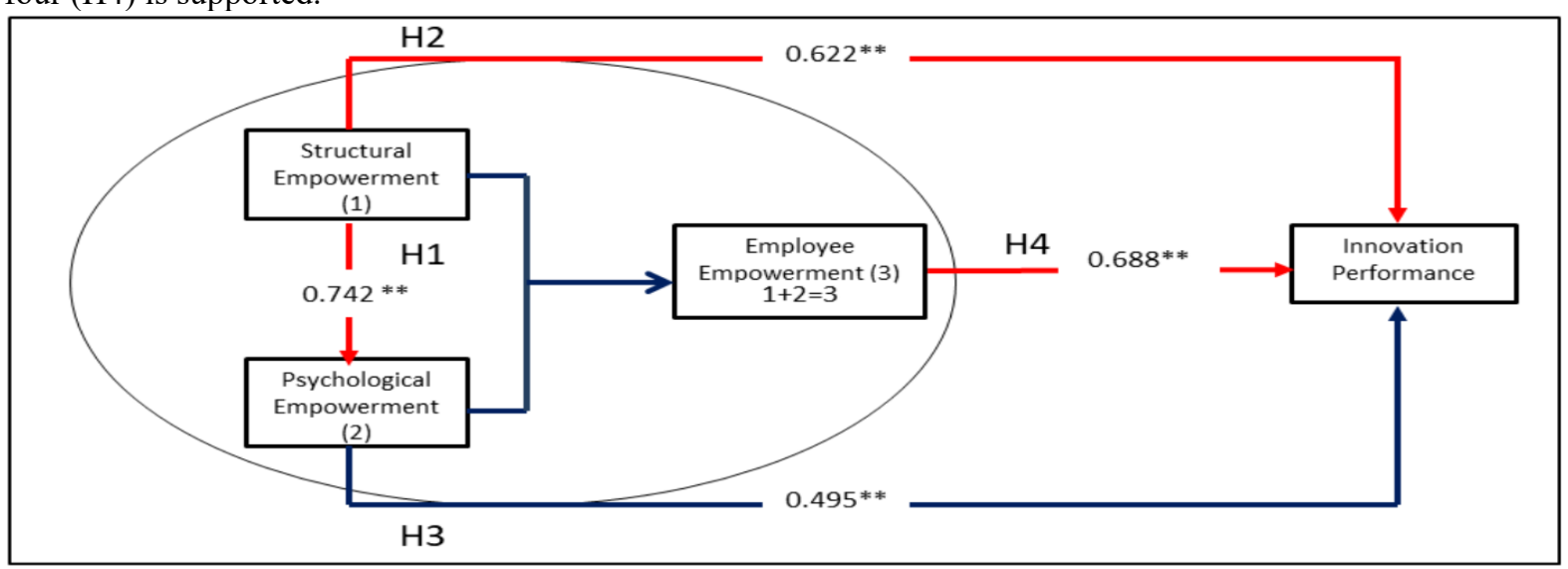

Figure 2: A Summary of the Results of the Research 


\section{Discussion}

From the literature review of empowerment and innovation performance, this research developed an instrument for measuring these variables in the Jordanian hotel industry. This research has performed exploratory factor analysis and regression analysis to validate and test the relationship between these variables using data from fivestar hotels in Jordan. The results of the exploratory factor analysis showed a difference between this research and other researches that measured the variables of this research. Therefore, it should be noted that the difference between this research and other researches is in the structure of the extracted factors of these variables.

More specifically, the result of structural empowerment as one-factor structure is consistent with many previous studies which considered structural empowerment as a one-factor construct (Hartline and Ferrell, 1996; Chebat and Kollias, 2000; Savery and Luks, 2001 and Al-Sabi, 2011). However, the only difference between this research and the previous researches was based on the number of the items that have been used to form structural empowerment. With regards to psychological empowerment as two-factor structure is somewhat contrary to expectations and different from the initial four factors extracted in sprietzer's scale, however the two factors are consistent with previous researches which considered psychological empowerment as a dual-factor construct (Kim and George, 2005 and Al-Sabi, 2011). For innovation performance as one-factor structure, the result reveals unexpected and different results from the initial two factors (product innovation and process innovation). The possible reason behind this is that the employees were unable to differentiate between these two factors 'product innovation' and 'process innovation' of the original scale of innovation performance in the Jordanian hotels.

Further to these results, this research has performed inter-item correlation test to make sure that the items of the extracted scale are correlated with each others as well as with the summated scales at the recommended values and consequently achieve the acceptable level of reliability. The result shows that the inter-item correlations are significant and exceed the accepted level of 0.30 as well as the correlations with the summated scales of structural empowerment, psychological empowerment and innovation performance which are all significant and above 0.50 . After all these results, this research confirms that structural empowerment, psychological empowerment, employee empowerment and innovation performance are approved effectively to be reliable and valid in a non-western context in general and in the Jordanian hotels in particular.

This research aimed to study the impact of empowerment on employees' innovation performance at five-star hotels in Jordan. First, the results of the regression analysis in this research provide a support for the significant effect of structural empowerment on psychological empowerment $\left(\mathbf{R}^{\mathbf{2}}=0.550, p=0.000\right)$. This explains that when the actions and behaviours of managers and supervisors are delivered properly to employees, this will develop an employment environment that will support them to take control of their own work and to form the feelings of psychological empowerment. This result also implies that the employees have perceived structural empowerment in the Jordanian hotels which in turn leads them to feel on psychological empowerment effectively. This result was supported with previous researches, which confirmed a significant relationship between structural empowerment and psychological empowerment (Sood, 2007 and Amenumey and Lockwood, 2008).

Second, this research also provides a support for the significant effect of structural empowerment on employees' innovation performance $\left(\mathbf{R}^{\mathbf{2}}=0.387, p=0.000\right)$. This result explains that creating an employment environment (structural empowerment), where the employees feel that they have the autonomy and the authority to act independently and take control of their work, will lead them to be more able to create and implement anything that boosts and achieves the organisational goals. It is worth noting here that structural empowerment was more significant predictor of employees' innovation performance than psychological empowerment. This implies that structural empowerment is a necessity for empowerment within service organisations, and will in turn lead automatically to the other elements of empowerment (psychological empowerment) and consequently lead to the achievement of the desired outcomes (innovation performance). Hence, these results are considered as major contributions for the literature of empowerment and innovation performance as most of the previous researches were focused on psychological empowerment rather than structure empowerment.

Third, this research also provides a support for the significant effect of psychological empowerment on employees' innovation performance $\left(\mathbf{R}^{\mathbf{2}}=0 . .245, p=0.000\right)$. This explains that when the employees have the confidence in their values and beliefs on how well they will perform their goals and tasks (attitude), and have the trust in their abilities and choices in influencing, initiating and regulating their own work (influence), they will be more able to create and implement anything (i.e products, services, ideas, procedures, policies,. etc) at all levels within the service organisations. This result also implies that the employees hold and perceived all the cognitions of psychological empowerment in the Jordanian hotels which in turn leads them to be more able go through innovation performance effectively. This result was supported with previous researches, which confirmed a significant relationship between psychological empowerment and innovation performance (Spreitzer 1995; Bolat 2008; Kahreh et al, 2011; Köksal, 2011; Bhatnagar, 2012; and Uzunbacak, 2015).

Fourth, on one hand most of the previous researches in the hospitality industry focused on measuring psychological empowerment and innovation performance rather than structural empowerment and none were 
focusing on both forms of empowerment Jointly on innovation performance on the other hand. The research's results argued that when structural empowerment and psychological empowerment are merged together as a whole, the influence of empowerment on employees' innovation performance shows a higher level $\left(\mathbf{R}^{\mathbf{2}}=0.473, p=0.000\right)$, which distinguishes this research from other researches were conducted. This result was supported by Uzunbacak (2015) who indicated that employees are appreciated the efforts of empowerment, participate in management, have the authority to make decisions and to produce new ideas and that managers attempt to create an environment which will facilitate employees' creativity and innovativeness encourages employees to behave innovatively. In this created environment (structural empowerment), the employee will feel empowered and be able to produce and implement new ideas (Köksal, 2011). This result implies that merging empowerment in the sequence of structural empowerment and then psychological empowerment will lead the employees at five-star hotels in Jordan to be more innovative in their work. In other words, the ability that the employer has to structurally empower his/her employees would affect the employees' assessment of psychological empowerment. Accordingly, employees will be more innovative at their work.

\subsection{Theoretical and Managerial Implications}

The results above provided the theoretical contributions to knowledge and reveal several important implications for theory and research of empowerment and innovation performance in the developing countries. The results indicated that structural empowerment scale with one-factor construct, psychological empowerment scale with two- factor construct, and innovation performance scale with one-factor construct are valid and reliable among employees working in five-star hotels in Jordan. Hence, the study's instrument can be used usefully in other studies with different contexts.

One of the main contributions of this research is that structural empowerment has a significant relationship with employees' innovation performance and is more significant predictor of employees' innovation performance than psychological empowerment at five-star hotels in Jordan. Moreover, this research also showed that psychological empowerment has a significant influence on employees' innovation performance. Another important contribution of this research is that most of the previous researches in the hospitality industry focused on measuring psychological empowerment on innovation performance rather than structural empowerment and none were focusing on both forms of empowerment jointly on innovation performance in a western context. This research is one of the first researches that attempts to adopt and measure the two perspectives of empowerment (structural empowerment and psychological empowerment) on employees' innovation performance in a nonwestern context. Accordingly, these results and contributions give more support for the validity of the translated scales, which can be used in future as a valid measures in the developing countries.

In this research, a number of managerial implications can be highlighted. First, it is necessary for managers to understand the important role that structural empowerment plays on employees' innovation performance. This can be done by benefit from training programs, rewarding systems and management styles which in turn lead the employees to act independently in innovation performance. Second, it is also important for the managers at all levels in Jordanian hotels to recognise the significant role of structural empowerment on psychological empowerment and consequently on employees' innovation performance. Third, it is useful for managers to take advantage of the designed instrument, evaluate and improve the provided level of both empowerment (structural empowerment and psychological empowerment) and innovation performance in the Jordanian hotels.

\subsection{Limitations and Future Research}

This research has some limitations which may require more attention when understanding the study's finding. Therefore, this research offers some recommendations for future research, as follows. First, it is limited to the fivestar hotels in Jordan, and thus, future researchers are advised to conduct and measure the model of this research in other service sectors in Jordan to have a better generalization of the findings. Second, investigating this research model in other service contexts from both managerial and customer perspectives, rather than concentrating on the employee perspective, may expand our knowledge with regard to the relationship between empowerment and innovation performance. Third, this research has measured the empowerment variable as a whole on innovation performance, and thus, future researchers are recommended to measure empowerment on innovation performance at the dimensional level and see their potential effects on each other would be an interesting research area. Fourth, this research has only focused on structural empowerment, psychological empowerment and innovation performance. Thus, future researchers are advised to look at other variables such as total quality management and this could also contribute to the knowledge between empowerment and innovation performance.

\subsection{Conclusion}

In conclusion, this research has provided a significant new contribution to research on empowerment and innovation performance. It has explored and verified outstanding findings that are related to the relationship between employee empowerment and employees' innovation performance. The results of this research have 
supported this relationship, bridged the gaps between empowerment and innovation performance literature and the empirical findings. The results are summarised in Fig. 2. All the relationships shown in the figure are statistically significant as shown in the tables of results in the testing hypotheses section. The red lines in the figure represent the strongest relationships in each of the regression analyses. Of these relationships, the relationship between structural empowerment and psychological empowerment which shows the strongest unique contribution on psychological empowerment. Next, the relationship between structural empowerment and innovation performance which shows a stronger unique contribution to innovation performance than the contribution of psychological empowerment does to innovation performance. Then, the relationship between employee empowerment, (i.e. both structural empowerment and psychological empowerment) and innovation performance which shows also the strongest relationship in the overall model on innovation performance than the relationship of structural empowerment and psychological empowerment do separately on innovation performance. The current study was conducted only in five-star hotels in Jordan, and as such the results are not claimed to be totally representative. They do however provide insights that can form the direction of future research into this important topic. It is the wish of the researchers that this contribution will be built upon by other researchers and practitioners, to shed further light on important aspects related to empowerment and innovation performance at the hotel industry in Jordan.

\section{References}

Al-Ababneh, M. (2014), “Employees' Service Innovation and Innovation Behaviour and New Development in Four- and Five-Star Hotels", International Journal of Tourism \& Hospitality Reviews, Vol. 1 (1), pp. 19-32.

Al-Sabi, S. (2011), The Effect of Empowerment on the Service Recovery Performance of Front Office Agents in Five Star Hotels in Jordan, $\mathrm{PhD}$ thesis, University of Surrey

Al Zahrani, A.A. et.al. (2012), "The Impact of Antecedents Supporting Organizational Innovation on Employees' Psychological Empowerment: An Empirical Study of Saudi and Jordanian Industrial Corporations", African Journal of Business Management, Vol. 6 (24), pp. 7329- 7343.

Amabile, T. M. (1996), Creativity in Context. Colorad: Westview Press, Inc.

Amabile, T. M. (1997), "Motivating Creativity in Organisation: On Doing What you Love and Loving What you Do", California Management Review, Vol. 40 (1), pp.39-58.

Amenumey, E. and Lockwood, A. (2008), "Psychological Climate and Psychological Empowerment: An Exploration in a Luxury UK Hotel Group", Tourism and Hospitality Research, Vol. 8 (4), pp. 265-281

Awamleh, N. A. H. K. (1994), "Managerial Innovation in the Civil Service in Jordan", Journal of Management Development, Vol. 13 (9), pp.52-60.

Basadur, M., Pringle, P. and Kirkland, D. (2002) "Crossing Cultures: Training Effects on the Divergent Thinking Attitudes of Spanish-Speaking South American Managers", Creativity Research Journal, Vol. 14 (3\&4), pp.395-408.

Bhatnagar, J. (2012), "Management of Innovation: Role of Psychological Empowerment, Work Engagement and Turnover Intention in the Indian Context", The International Journal of Human Resource Management, Vol. 23 (5), pp. 928-951.

Biron, M. and Bamberger, P. (2010), "The Impact of Structural Empowerment on Individual Well-Being and Performance: Taking Agent Preferences, Self-Efficacy and Operational Constraints Into Account", Human Relations, Vol. 63 (2), pp. 163-91.

Black, J. S. and Porter, L.W. (2000), Management. Prentice Hall, Inc.

Bolat, T. (2008), Dönü_ümcü Liderlik, Personeli Güçlendirme ve Örgütsel Vatanda_lık Davranı_li_kisi, Baskl, Ankara: Detay Anatolia Yayıncılık. CHOONG

Bowen, D. E. and Lawler, E. E. (1992), "The Empowerment of Service Workers: What, Why, How, and When”, Sloan Management Review, Vol. 33 (3), pp. 31-39.

Briggs, S. R. and Cheek, J. M. (1986), "The Role of Factor Analysis in the Development and Evaluation of Personality Scales", Journal of Personality, Vol. 54, pp. 106-48.

Chebat, J. C. and Kollias, P. (2000), "The Impact of Empowerment on Customer Contact Employees' Roles in Service Organisations", Journal of Service Research, Vol. 3 (1), pp. 66-81.

Cho, S. Woods, R. H. Jang, S. S. and Erdem, M. (2006), "Measuring the Impact of Human Resources Management Practice on Hospitality Firms' Performances", Hospitality Management, Vol. 25, pp. 262- 277.

Çuhadar, M.T. (2005), "Türk Kamu Yönetiminde Personel Güçlendirme: Sorunlar ve Çözüm Önerileri”, $B F$ Journal, Vol. 25, pp. 1-25.

Daft, R.L. (1982), "Bureaucratic Versus Non-Bureaucratic Structure and the Process of Innovation and Change", In: Bacharach S.B. (Ed.), Research in the Sociology of Organizations, Greenwich, CT: JAI Press, (1), pp. $129-66$.

Damanpour, F and William M. Evan. (1984) "Organizational Innovation and Performance: The Problem of Organizational Lag”, Administrative Science Quarterly, Vol. 2, pp. 392-409. 
Erstad, M. (1997), "Empowerment and Organizational Change", International Journal of Contemporary Hospitality Management, Vol. 9 (7), pp. 325-333.

Ergun, R. (2018), “The Mediating Role of Empowerment on the Relationship between Organizational Culture and Innovation Performance", Journal of Entrepreneurship and Innovation Management, Vol. 7 (1), pp. 53-74.

Eylon, D., and Bamberger, P. (2000), "Empowerment Cognitions and Empowerment Acts: Recognise the Importance of Gender", Group and Organization Management, Vol. 25 (4), pp. 354-372.

Ford, C. M. (1996), “A Theory of Individual Creative Action in Multiple Social Domains", Academy of Management Review, Vol. 21 (4), pp. 1112-1142.

Ginnodo, B. (1997), The Power of Empowerment. Arlington Heights, Illinois: Pride Publications, Inc

Hair, J. F. Jr. Black, W. C. Babin, B. J. Anderson, R. E. and Tatham, R. L. (2006), Multivariate Data Analysis. Prentice-Hall: New Jersey.

Hair, J. F. Jr. Black, W. C. Babin, B. J. Anderson, R. E. and Tatham, R. L. (2010), Multivariate Data Analysis. Prentice-Hall: New Jersey.

Harrington, R. J. (2004) "Part I: the Culinary Innovation Process, a Barrier to Imitation", Journal of Foodservice Business Research, Vol. 7 (3), pp.35-57.

Hartline, M. D. and Ferrell, O. C. (1996), "The Management of Customer-Contact Service Employees: An Empirical Investigation", Journal of Marketing, Vol. 60 (Oct), pp. 52-70.

Hayes, B. E. (1994), "How to Measure Empowerment”, Quality Progress, Vol. 27 (2), pp.41-6.

Herbig, P. and Jacobs, L. (1996) "Creative Problem-Solving Styles in the USA and Japan", International Marketing Review, Vol. 13 (2), pp.63-71.

Johnson, R., and Redmond, D. (1998), The Art of Empowerment: The Profit and Pain of Employee Involvement. London: Financial Times Management.

Kahreh, M.S. (2011), "Achieving Competitive Advantage Though Empowering Employees: An Empirical Study", Fast East Journal of Psychology and Business, Vol. 3 (2), pp. 26-37.

Kanter, R. M. (1983), "Frontiers for Strategic Human Resource Planning and Management", Human Resource Management, Vol. 22 (1/2), pp. 9-21.

Kemp, S. and Dwyer, L. (2001), "An Examination of Organizational Culture - the Regent Hotel, Sydney", International Journal of Hospitality Management, Vol. 20, pp. 77-93.

Kim, B. and George, R. T. (2005), "The Relationship between Leader-Member Exchange (LMX) and Psychological Empowerment: A Quick Casual Restaurants Employee Correlation Study", Journal of Hospitality and Tourism Research, Vol. 29 (4), pp. 468-483.

Klidas, A. K. (2001), Employee Empowerment in the European Hotel Industry: Meaning, Process and Culture Relativity, Thela Thesis, Rozengracht 176A, 1016 NK Amsterdam

Koksal, O. (2011), “Organizasyonel Etkinli_in Sa_Lanmasının Yeni Yolu: Dimbiyotik Liderlik”, BF Journal, Vol. $12(1)$, pp. 55-72.

Kruja, D., Ha, H., Drishti, E., \& Oelfke, T. (2016). "Empowerment in the hospitality industry in the United States", Journal of Hospitality Marketing \& Management, Vol. 25(1), pp. 25-48.

Lashley, C. (1995), "Towards an Understanding of Employee Empowerment in Hospitality Services", International Journal of Contemporary Hospitality Management, Vol. 7 (1), pp. 27-32.

Lashley, C. (1999), "Employee Empowerment in Services: a Framework for Analysis", Personnel Review, Vol. 28 (3), pp. 169-191.

Lashley, C. (2001), Empowerment HR Strategies for Service Excellent. Linacre House, Jordan Hill, Oxford: Elsevier Butterworth Heinemann.

Lee, M. and Koh, J. (2001) "Is Empowerment Really a New Concept?", The International Journal of Human Resource Management, Vol. 12 (4), pp. 684-695.

Martins, E. C. and Terblanche, F. (2003), "Building Organisational Culture that Stimulates Creativity and Innovation", European Journal of Innovation Management, Vol. 6 (1), pp.64-74.

Melhem, Y. (2004), “The Antecedents of Customer-Contact Employees' Empowerment”, Employees Relations, Vol. 26 (1), pp. 72-93.

Mills, P. K. and Ungson, G. R. (2003), "Reassessing the Limits of Structural Empowerment: Organisational Constitution and Trust as Control", Academy of Management Review, Vol. 28 (1), pp. 143-153.

Ministry of Tourism and Antiquities Jordan. (2019). "Statistics". Retrieved September 4, 2019, from https://www.mota.gov.jo/Contents/stat2019 2nd.aspx

Mostafa, M. (2005), "Factors Affecting Organisational Creativity and Innovativeness in Egyptian Business Organisations: An Empirical Investigation", Journal of Management Development, Vol. 24 (1), pp.7-33.

Nadeem, M.T. Zia-uD-din, M. Riaz, W. Shafique, M.Z. and Sattar, A. (2018), "The Effect of Employees Empowerment on Organisational Performance: A Case of Hotel Industry in Pakistan”, International Journal of African and Asian Studies, Vol. 47, pp. 89-94.

Odeh, K. A. (2008), The Impact of Front line Employee Empowerment on Service Quality in the Jordanian 
Restaurant Industry, PhD thesis, University of Surrey.

Oldham, G. R. and Cummings, A. (1996), "Employee Creativity: Personal and Contextual Factors at Work", The Academy of Management Journal, Vol. 39 (3), pp.607-634.

Ottenbacher, M. and Gnoth, J. (2005) "How to Develop Successful Hospitality Innovation", Cornell Hotel and Restaurant Administration Quarterly, Vol.46 (2), pp.205-222.

Ottenbacher, M. and Harrington, R. J. (2007) "The Innovation Development Process of Michelin-Starred Chefs", International Journal of Contemporary Hospitality Management, Vol.19 (6), pp.444-460.

Pallant, J. (2010), SPSS Survival Manual. England: McGraw-Hill Education.

Prajogo, D. I. and Sohal, A. S. (2003), "The Relationship between TQM Practices, Quality Performance, and Innovation Performance: An Empirical Examination”, International Journal of Quality and Reliability Management, Vol. 20 (8), pp. 901-918.

Quinn, R. E. and Spreitzer, G. M. (1997), "The Road to Empowerment: Seven Questions Every Leader Should Consider", Organization Dynamics, Vol. 26 (2), pp. 37-49.

Rafiq, M., and Ahmed, P. K. (1998), "A Customer-Oriented Framework for Empowering Service Employees", Journal of Services Marketing, Vol. 12 (5), pp. 279-396.

Randolph, W. A. and Sashkin, M. (2002), “Can Organisational Empowerment Work in Multinational Settings?”, Academy of Management Executive, Vol. 16 (1), pp. 102-115.

Rodriguez, P. R. Hechanova, M. and Regina, M. (2014), "A Study of Culture Dimensions Organizational Ambidexterity, and Perceived Innovation in Teams", Journal of Technology Management and Innovation, Vol. 9 (3), pp. 21-33.

Savery, L. K. and Luks, J. A. (2001), "The Relationship between Empowerment, Job Satisfaction and Reported Stress Levels: Some Australian Evidence”, Leadership and Organisation Development Journal, Vol. 22 (3), pp. 97104.

Scott, S. G. and Bruce, R. A. (1994), "Determinants of Innovative Behaviour: A Path Model of Individual Innovation in the Workplace", Academy of Management Journal, Vol. 37 (3), pp.580-607.

Seibert, S. E. Silver, S. R. and Randolph, W. A. (2004), "Taking Empowerment to the Next Level: A MultipleLevel Model of Empowerment Performance, and Satisfaction", Academy of Management Journal, Vol. 47 (3), pp. 332-34.

Spreitzer, G. M. (1995), "Psychological Empowerment in the Workplace: Dimensions, Measurement, and Validation", Academy of Management Journal, Vol. 38 (5), PP. 1442-1465.

Spreitzer, G. M. (1996), "Social Structural Characteristics of Psychological Empowerment", Academy of Management Journal, Vol. 39 (2), pp. 483-504.

Sreenivas, J.N.G. (2014), "The Impact of Psychological Empowerment on Employee Performance: A Conceptual Review”, Journal of Business Management, Vol. 16 (6), pp. 1-5.

Sood, A. (2007), Empowerment Effects Across Cultures, PhD thesis, Aston University.

Thomas, K. W. and Velthouse, B. A. (1990), "Cognitive Elements of Empowerment: An Interpretive Model of Intrinsic Task Motivation”, Academy Management Review, Vol. 15 (4), pp. 666-681.

Ueno, A. (2008), “Is Empowerment Really a Contributory Factor to Service Quality?”, Service Industries Journal, Vol. 28 (9), pp. 1321-37.

Uzunbacak, H.H. (2015), “The Impact of Employee Empowerment on Innovation: A Survey on Isparta and Burdur Organised Industrial Zones”, Journal of International Social Research, Vol. 8 (37), pp. 977-989.

Wong, S. and Pang, L. (2003) "Motivators to Creativity in the Hotel Industry-Perspectives of Managers and Supervisors", Tourism Management, Vol.24, pp.551-559. 